\title{
Erratum to: Antimetastatic activity of MONCPT in preclinical melanoma mice model
}

\author{
Xiao-Chun Yang • Chong-Xing Tu • Pei-Hua Luo • \\ Hong Zhu $\cdot$ Di-Feng Zhu $\cdot$ Hong-Hai Wu \\ Xing-Lu Zhou • Wei Lu • Qiao-Jun He • Bo Yang
}

Published online: 12 June 2010

(C) Springer Science+Business Media, LLC 2010

\section{Erratum to: Invest New Drugs}

\section{DOI 10.1007/s10637-009-9323-8}

Unfortunately, an error occurred in the address of the author, Wei Lu. The correct address of the author is stated below.

The online version of the original article can be found at http://dx.doi. org/10.1007/s10637-009-9323-8.

X.-C. Yang $\cdot$ C.-X. Tu $\cdot$ P.-H. Luo $\cdot$ H. Zhu $\cdot$ D.-F. Zhu $\cdot$

H.-H. Wu $\cdot$ X.-L. Zhou $\cdot$ Q.-J. He $(\square) \cdot$ B. Yang $(\square)$

Institute of Pharmacology and Toxicology,

College of Pharmaceutical Sciences, Zhejiang University,

Hangzhou, Zhejiang, People's Republic of China

e-mail: qiaojunhe@zju.edu.cn

e-mail: yang924@zju.edu.cn

W. $\mathrm{Lu}$

Institute of Medicinal Chemistry, Department of Chemistry,

East China Normal University,

Shanghai, People's Republic of China 